\title{
Innovación en el diseño de centrales hidroeléctricas a principios de siglo XX. La ingeniería arquitectura de Casto Fernández-Shaw en la presa de La Jándula
}

\section{Innovation in hydroelectric power plant design in early twentieth century. Casto Fernández-Shaw's Engineering Architecture in La Jándula dam}

\author{
A. B. Berrocal Menárguez ${ }^{(*)}$, P. Molina Holgado ${ }^{(* *)}$, R. del Cuvillo Martínez-Ridruejo ${ }^{(*)}$
}

\section{RESUMEN}

La ubicación de la sala de máquinas fue un factor relevante en las primeras presas hidroeléctricas de finales del siglo XIX y principios del XX, que originó el ensayo de distintas soluciones, algunas de ellas con resultados estéticos e implicaciones hidráulicas y estructurales de gran interés. Tal es el caso de la presa de La Jándula, inaugurada en 1930, que incorporaba la central en el seno del cuerpo de presa. El artículo indaga los posibles antecedentes nacionales e internacionales de esta solución tan singular, corroborando la hipótesis de su carácter inédito. La colaboración del arquitecto Casto FernándezShaw en el diseño e integración de la sala de máquinas fue decisiva, ya que logró un resultado de una calidad estética y una expresividad formal sin precedentes en una obra de ingeniería hidráulica, así como el nacimiento de un estilo que el propio Shaw definiría como ingeniería arquitectura.

Palabras clave: ingeniería hidroeléctrica; Jándula (La); presa; arquitectura; central hidroeléctrica.

\section{ABSTRACT}

The power plant location in the first hydroelectrial dams was a relevant issue at the end of XIX century and early XX. Different solutions were tried, some of them with very interesting aesthetics results and hydraulic and structural implications. Such is the case of La Jándula dam, inaugurated in 1930, that includes the power station inside the dam. This article examines the possible national and international inspirations of this singular solution, corroborating the hypothesis of its unprecedented nature. The collaboration of the architect Casto Fernández-Shaw in the design and integration of the engine room was decisive, because it achieved a result of an aesthetic quality and formal expressiveness unprecedented in a work of hydraulic engineering, as well as the birth of a style Shaw himself defined as architectural engineering.

Keywords: hydroelectrical engineering; Jándula (La); dam; architecture; power station.

(*) E.T.S.I. Caminos, Canales y Puertos, Departamento de Ingeniería Civil: Transporte y Territorio. UPM. Madrid. España

(**) Facultad de Filosofía y Letras. Departamento de Geografía. UAM. Madrid. España

Persona de contacto/Corresponding author: anabelen.berrocal@upm.es (A. B. Berrocal Menárguez)

ORCID: http://orcid.org/oooo-0oo1-9777-6216 (A. B. Berrocal Menárguez); http://orcid.org/oooo-0001-6129-5648

(P. Molina Holgado); http://orcid.org/oooo-0oo1-8070-9762 (R. del Cuvillo Martínez-Ridruejo)

Cómo citar este artículo/Citation: Berrocal Menárguez, A. B., Molina Holgado, P., Cuvillo Martínez-Ridruejo, R. del (2017). Innovación en el diseño de centrales hidroeléctricas a principios de siglo XX. La ingeniería arquitectura de Casto Fernández-Shaw en la presa de La Jándula. Informes de la Construcción, 69(547): e206, doi: http://dx.doi.org/10.3989/ic.16.062.

Copyright: (C) 2017 CSIC. Licencia / License: Salvo indicación contraria, todos los contenidos de la edición electrónica de Informes de la Construcción se distribuyen bajo una licencia de uso y distribución Creative Commons Attribution License (CC BY) Spain 3.o. 


\section{LA RACIONALIZACIÓN EN EL DISEÑO DE PRESAS. NUEVO PARADIGMA DE LA MODERNIDAD}

Los avances técnicos en el campo de la energía hidráulica experimentados en los últimos años del siglo XIX y primeros del XX supusieron una revolución en la ingeniería de presas en todo el mundo (1). La búsqueda de saltos hidráulicos cada vez mayores y la optimización de los procesos de generación de energía contribuyeron de forma decisiva a la búsqueda de nuevas soluciones estructurales, constructivas y formales (2). La ingeniería de presas se benefició, además, de la corriente progresista, de profunda transformación económica, tecnológica y social que impregnaba prácticamente todos los sectores productivos. Sin embargo, la Revolución Industrial no se manifestó con la misma intensidad ni al mismo tiempo en todos los países occidentales, como bien se sabe. Este desfase tendría consecuencias apreciables también en el ámbito de las construcciones civiles, particularmente en la ingeniería de presas.

La revolución de la técnica hidráulica se daría como consecuencia de la aplicación de los principios de la mecánica racional al proyecto de la obra (3). Durante los últimos años del siglo XIX y primeros del XX se realizan pocas pero muy significativas presas que utilizan la mecánica racional como base científica de su diseño. El éxito de las mismas hizo posible el gran auge de la construcción de presas del siglo XX.

Los primeros avances se produjeron en el campo de las presas de materiales sueltos, aunque poco después la ingeniería hidráulica de presas de fábrica se vio favorecida por la determinación del perfil teórico más ventajoso en términos de consumo de material y con garantías de estabilidad, determinado por el ingeniero francés Sazilly, utilizando criterios de mecánica racional en sus aproximaciones.

Estas aproximaciones teóricas al perfil estable más rentable y seguro para una presa de fábrica demostraron que se correspondía con un triángulo con el paramento de aguas arriba vertical. Pero la primera realización práctica vino de la mano de otro ingeniero de Ponts et Chausées, Èmile Delocre, quien acabó en 1866 la presa de Furens (4). Esta presa medía 60 m de altura, es decir, era notablemente más alta que cualquier otra construida hasta la fecha. Era de mampostería y tenía los paramentos ligeramente cóncavos a ambos lados. Además, tenía planta levemente curva, algo ya experimentado con éxito, aunque todavía no racionalizado, en las presas alicantinas de Tibi, Almansa o Elche (estudiadas por el propio Delocre para el desarrollo de su modelo matemático).

Otro factor de enorme importancia fue el comienzo del empleo del hormigón. Las presas hasta entonces se construían en piedra: mampostería no muy cuidada en el interior, con paramentos de sillería mejor trabajada y de piedra más re- sistente. Desde los romanos, que sí utilizaban hormigón en sus presas, no se volvió a utilizar éste hasta 1872, cuando se construyeron dos presas, una en Suiza y otra en EE.UU. La utilización del hormigón supuso un salto cuantitativo en la altura de las presas, convirtiéndose en el material idóneo para su construcción.

En España existe una colección de presas de este primer periodo no muy abundante, pero sí muy representativa, tales como El Villar (1882, $50 \mathrm{~m}$ ), el conjunto del ámbito minero de las sierras de Huelva (1878-1887), Puentes III (1884), El Regato $(1897,20 \mathrm{~m})$ o La Peña $(1913,61 \mathrm{~m})$. Casi todas las presas de cierta entidad de este periodo se caracterizan por la innovación en uno o varios de sus elementos constitutivos, materiales empleados o formas definidas en el cuerpo de presa o en los órganos de desagüe. Estos últimos años del siglo XIX y la primera década del XX sentaron las bases de una ingeniería hidráulica española que destacaría en las siguientes décadas por realizaciones pioneras, soluciones audaces despojadas de complejos y composiciones de una enorme calidad estética, que competirían al más alto nivel internacional.

\section{EL DISEÑO Y UBICACIÓN DE LA SALA DE MÁQUINAS EN LAS PRESAS HIDROELÉCTRICAS DE PRINCIPIOS DE SIGLO XX. EL NACIMIENTO DE LAS CENTRALES HIDROELÉCTRICAS INTEGRADAS EN EL CUERPO DE PRESA}

\subsection{Antecedentes españoles}

La Jándula, una de las realizaciones más bellas y singulares de la ingeniería hidráulica española, se construye en 1932 (aunque su proyecto definitivo data de 1927) con el objeto de regular el río de nombre homónimo, afluente directo del Guadalquivir por margen derecha aguas abajo de Andújar, y de generar energía eléctrica gracias al salto de casi $90 \mathrm{~m}$ que genera su presa. Los motivos, técnicos y estéticos, que justifican la importancia y singularidad de La Jándula son múltiples, pero sin duda la morfología y disposición de la central, embebida parcialmente en el cuerpo de presa, es el factor más relevante. El aprovechamiento hidroeléctrico en España mediante grandes presas arranca sólo dieciséis años antes con la inauguración de Talarn, una obra de $86 \mathrm{~m}$ de altura sobre el impetuoso río leridano Noguera Pallaresa. Durante los diez años que trascurren desde la ejecución de Talarn (1916) y la redacción del proyecto definitivo de La Jándula tan sólo se construyen en España 3 presas hidroeléctricas de altura superior a $60 \mathrm{~m}$ (5) (Tabla 1).

Ninguna de las presas anteriores a La Jándula había resuelto la central hidroeléctrica incorporándola al cuerpo de presa. Todas ellas separan estructural y funcionalmente la pantalla del edificio de turbinas. No cabe duda de que el alojamiento de los equipos hidroeléctricos en un edificio exento al cuerpo

Tabla 1. Presas hidroeléctricas superiores a $60 \mathrm{~m}$ construidas en España antes del proyecto definitivo de La Jándula. Elaboración propia a partir de datos de SEPREM

\begin{tabular}{|l|l|c|c|}
\hline \multicolumn{1}{|c|}{ Nombre } & \multicolumn{1}{|c|}{ Cuenca } & Altura & Año \\
\hline Talarn & Ebro & 86 & 1916 \\
\hline Camarasa & Ebro & 103 & 1920 \\
\hline Conde de Guadalhorce & C. mediterránea andaluza & 74 & 1921 \\
\hline Montejaque & Guadalquivir & 84 & 1924 \\
\hline
\end{tabular}


de presa era una solución cautelosa frente a posibles daños debidos a filtraciones o desbordamientos, una solución casi obligada, sobre todo en aquellos primeros años de ensayo y aprendizaje. Por tanto, siempre y cuando la cerrada permitiese el alojamiento de las instalaciones hidroeléctricas aguas abajo con cierto desahogo, la separación de funciones era clara. Del mismo modo sucedía con los elementos de desagüe de avenidas, que tras los problemas de socavación de cimentaciones en presas históricas con vertido por coronación, se opta de forma general por apartarlos nítidamente de la propia pantalla. Estas reservas exigían en algunos casos costosas obras para llevar los vertederos por collados aledaños, devolviendo los caudales al cauce a suficiente distancia del cuerpo de presa.

En presas de modestas dimensiones, auxiliares a molinos hidráulicos, existen tipologías en nuestro país en las que la sala de molienda está adosada al cuerpo de presa, llegando, en algunas realizaciones, a participar estructuralmente en la resistencia del muro. Tal es el caso, por ejemplo, de las presas de cubo adosadas a una balsa, en las que, por la propia configuración del conjunto, la sala de molienda precisa ser situada junto al muro de contención. Existen ejemplos relevantes de esta solución en buena parte de la geografía española, aunque quizás una de las zonas mejor estudiadas haya sido Cáceres, con los trabajos de García-Diego (6). Estas realizaciones, aunque aún distantes formalmente de la solución de La Jándula y previas al nacimiento de los aprovechamientos hidroeléctricos, pueden considerarse el germen de las centrales hidroeléctricas situadas en el pie de presa y, por extensión, de las embebidas en la propia estructura.

Ya en el siglo XX y para uso hidroeléctrico, en España, hubo una realización previa al proyecto definitivo de La Jándula en la que se integraba la central en el cuerpo de presa. Se trata del salto de Gaitanejo (1927), en la localidad malagueña de Ardales (véase Figura 1). Esta obra fue proyectada y construida por Rafael Benjumea, fundador de la compañía de El Chorro, quien había sido reconocido con el título de Conde de Guadalhorce por su papel protagonista en la regulación del río Guadalhorce para el suministro de energía eléctrica a la ciudad de Málaga. La presa de Gaitanejo se proyectó como salto hidroeléctrico reversible, auxiliar a la presa de Conde de Guadalhorce (1921), situada inmediatamente aguas arriba

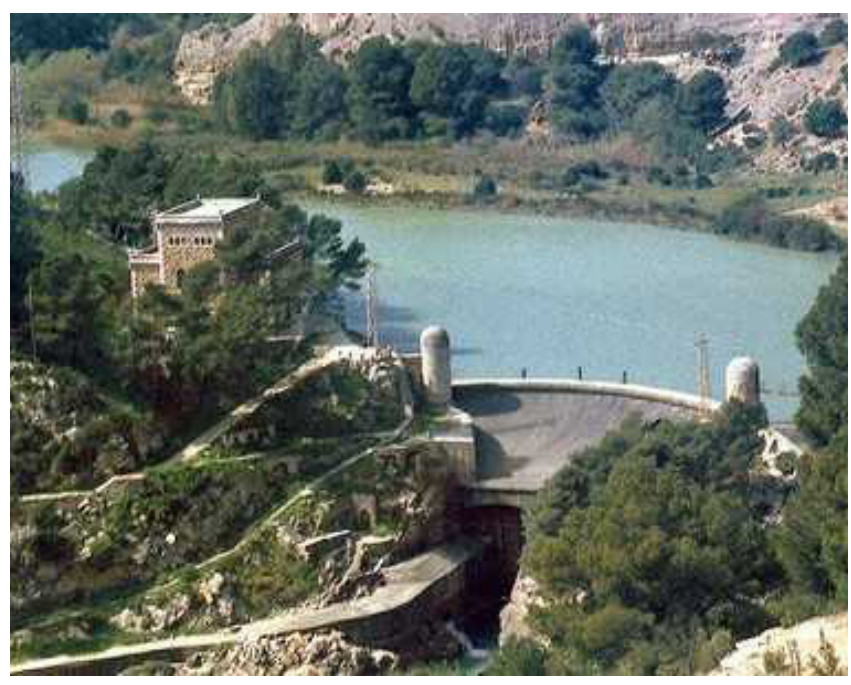

Figura 1. Vista oblicua de la presa de Gaitanejo (Fuente: Instituto Andaluz del Patrimonio Histórico). del nuevo embalse (7). Si bien es cierto, como se ha afirmado, que su diseño incorporaba por primera vez en España la central en el seno de la propia presa, también hay que tener en consideración que se trata de una obra de relativa poca entidad, aunque expuesta a las avenidas de los ríos Guadalhorce y Guadalteba, y a resguardo de las crecidas del Turón, como consecuencia del efecto laminador de la presa del Conde de Guadalhorce. Se trata, por tanto, de una obra modesta en dimensiones pero muy correcta técnicamente, en particular en su resistencia a eventos hidráulicos extraordinarios. Por tanto, sin desmerecer en absoluto la aportación técnica y conceptual del salto de Gaitanejo, puede afirmarse que la presa de La Jándula se enfrentaba casi sin antecedentes nacionales a una solución constructiva no exenta de importantes riesgos.

Aunque no se han encontrado referencias escritas sobre la influencia que el salto malagueño pudo causar en el lápiz de Fernández-Shaw, se puede afirmar sin riesgo a equivocarse que este último, así como todo el equipo de la ingeniería Mengemor que intervino en el proyecto y construcción de La Jándula, era perfectamente conocedor de la obra de Rafael Benjumea.

Los indicios que corroboran tal afirmación son múltiples. Por un lado, la compañía de El Chorro y su actividad de suministro eléctrico a la ciudad de Málaga no debió pasar precisamente desapercibida en la sociedad ilustrada de la época. Fue una de las empresas pioneras españolas en la carrera hidroeléctrica y de las más sonadas por su repercusión social y mediática (8). Precisamente, como se ha indicado, tal éxito le valió a su fundador, Rafael Benjumea, el reconocimiento del título nobiliario de Conde otorgado por Alfonso XIII en 1921, y poco después, ya bajo la dictadura de Primo de Rivera, la designación como Ministro de Obras Públicas (19251930), cargo que desempeñaría, por cierto, durante todo el proceso de aprobación del proyecto definitivo y construcción de La Jándula (9). Finalmente, y por si estos datos no fuesen concluyentes, el grupo de El Chorro había competido con la empresa Mengemor, liderada por Carlos Mendoza Sáez de Argandoña, coautor de La Jándula, en la concesión de esta obra entre 1920 y 1924, año en el que se otorga definitivamente la autorización a Mengemor, estimándose el proyecto de La Jándula como complementario del de Canalización y aprovechamiento del Guadalquivir, que la empresa tenía ya en tramitación (10). Numerosas conexiones, por tanto, entre los principales autores de ambas obras como para poder suponer que hubo una influencia directa entre Gaitanejo y La Jándula. La Figura 2 muestra esquemáticamente las relaciones personales y profesionales que se establecieron entre los autores de ambas presas.

La diferencia de altura entre ambas presas y de protección frente a las avenidas situaba, sin embargo, a Gaitanejo como simple referente estético para La Jándula, pero no suponía, en ningún caso, un ensayo válido que garantizase el éxito de la presa jienense. De hecho, la decisión final de integrar la casa de bombas en el cuerpo de la presa se realiza después de varios diseños previos en los que se prevé un edificio exento ubicado a distancias variables según las versiones, pero en todo caso alejado del pie de presa (11) (12).

\subsection{Antecedentes internacionales}

Resulta más difícil saber las influencias que el equipo de diseño de la presa de La Jándula, en particular el arquitecto Casto 


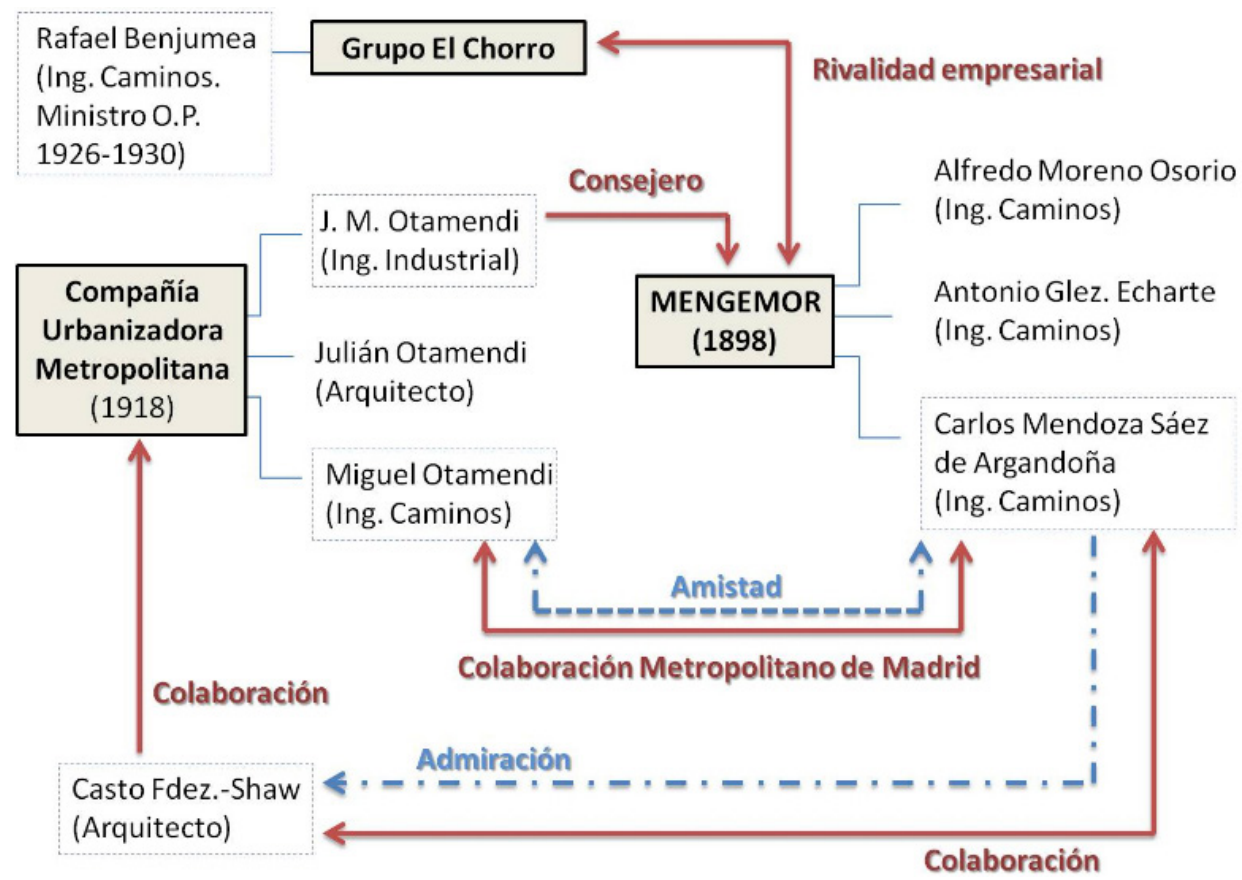

Figura 2. Esquema gráfico de las relaciones personales (en azul) y profesionales (en rojo) entre los autores de la presa de La Jándula y la presa de El Chorro.

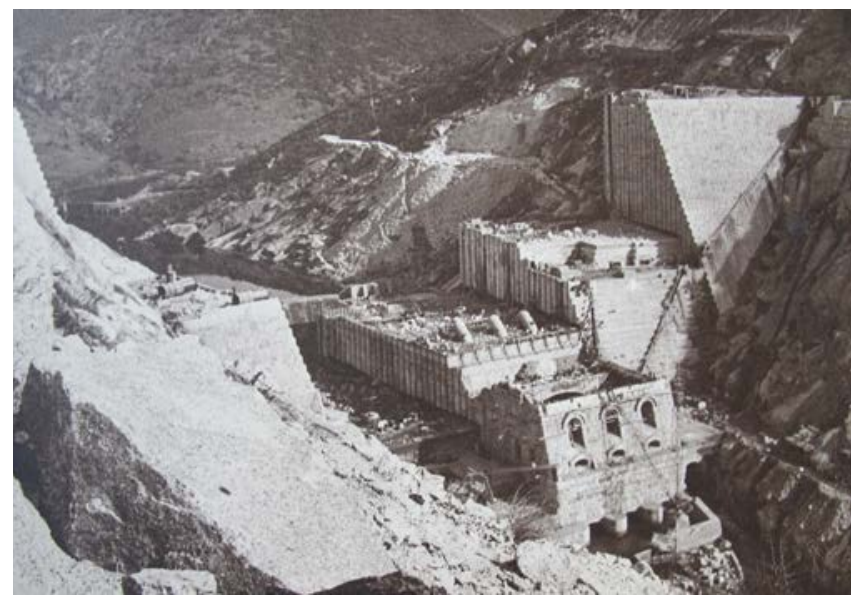

Figura 3. Vista de la presa de La Jándula en construcción, 1 de diciembre de 1928. (Fuente: Cía. de Canalización y Fuerzas del Guadalquivir) (13).

Fernández-Shaw, pudo tener de otras realizaciones anteriores en el extranjero, puesto que no existe ningún documento de los autores en este sentido. Sin embargo, son muy escasas las obras que incorporan la central en el seno de la propia presa que se construyeron en el mundo hasta ese momento (14) (véase Figura 3).

La primera realización de un salto hidroeléctrico en el que los equipos se sitúan dentro del cuerpo presa es la Bloede's dam, una presa de gravedad construida en hormigón de apenas 8 $\mathrm{m}$ de altura, cuyo nombre se debe al ingeniero de origen alemán, Victor Gustav Bloede, fundador de la compañía Avalon Water Works, responsable de su construcción (15). La presa data de 1907 y se encuentra cerca de la ciudad de Baltimore, sobre el río Patapsco. En su definición se contó con la colaboración del ingeniero eléctrico Otto Wonder y se instalaron los equipos hidroeléctricos más modernos hasta entones, formados por turbinas de eje horizontal Samson y ruedas hi- dráulicas Poole \& Hunt Leffel, de diámetros inferiores a un metro (16) (véanse Figuras 6 y 7). El diseño de esta presa se basa en la tipología de presa de núcleo hueco, constituida por una losa de hormigón reforzado, apoyada sobre contrafuertes, que fue patentada por Ambursen Hydraulic Construction Company, en 1904 (17) (18). En efecto, la patente atrajo la atención de la prensa especializada tras la realización de Warrior Ridge Dam en 1904, y otros constructores copiaron el modelo en sus realizaciones, a pesar de los esfuerzos de Ambursen por defender en los tribunales la exclusividad del diseño y de cualquier variante (véase Figura 4).

La tipología patentada por la compañía del ingeniero de origen noruego afincado en Estados Unidos, Nils F. Ambursen, en realidad recuperaba y adaptaba el antiguo diseño de presas de fábrica de arcos múltiples, antiguamente utilizado en diversas partes del mundo, o de madera, con hastiales inclinados. En este sentido, la primera descripción conocida de una presa de arcos múltiples con el paramento de aguas arriba inclinado es la del Código del español Juanelo Turriano del siglo XVI (19) (véase Figura 5). La patente de Ambursen, por tanto, no suponía una solución inédita, como así recogía la sentencia de uno de los pleitos interpuestos por la compañía: «El tipo Ambursen es sustancialmente una reproducción en hormigón de las presas antiguas y de pequeña entidad construidas en madera» (op. cit., 14). Así las cosas, esta solución, que ahorraba en torno a un $40 \%$ de material, fue replicada especialmente en Estados Unidos. De tales reproducciones interesa especialmente la ya citada Bloede's dam, al aprovechar el espacio libre del núcleo de este tipo constructivo para ubicar por primera vez en la historia de la ingeniería hidroeléctrica la sala de máquinas en el seno de la presa.

Esta obra muestra notables similitudes formales con las presas españolas de Gaitanejo y La Jándula, ya que en todas ellas destaca el abombamiento del paramento de aguas abajo necesario para acoger los equipos, y su curvatura responde a criterios hidrodinámicos de eventuales vertidos sobre co- 


\title{
1,033,988.
}

\author{
ㄱ. I. COBURN. \\ REITFOROED OONCRETE DAM. \\ APPLIOATIOS FILED FEB, 25, 1908.
}

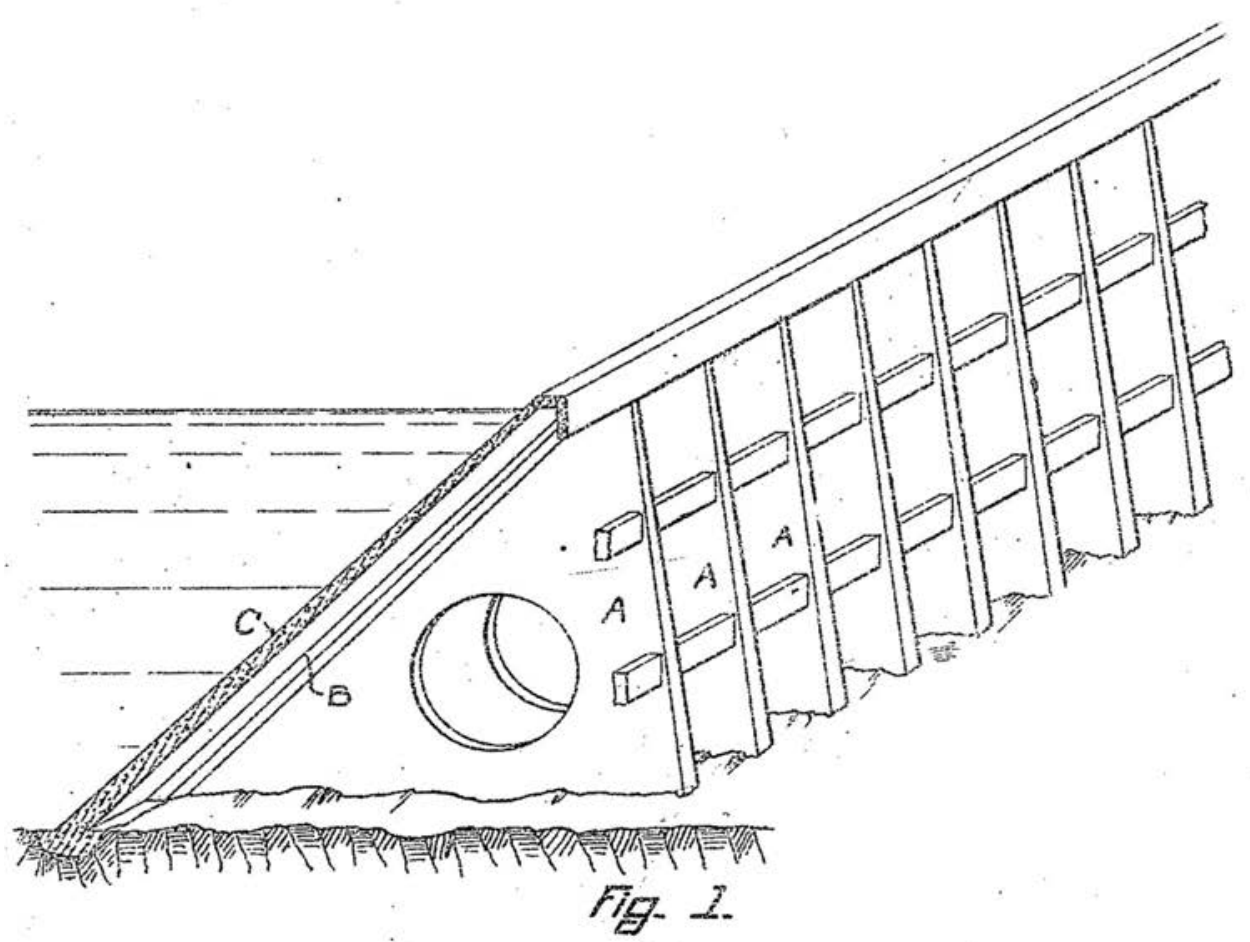

Patonteả July 30, $1:$

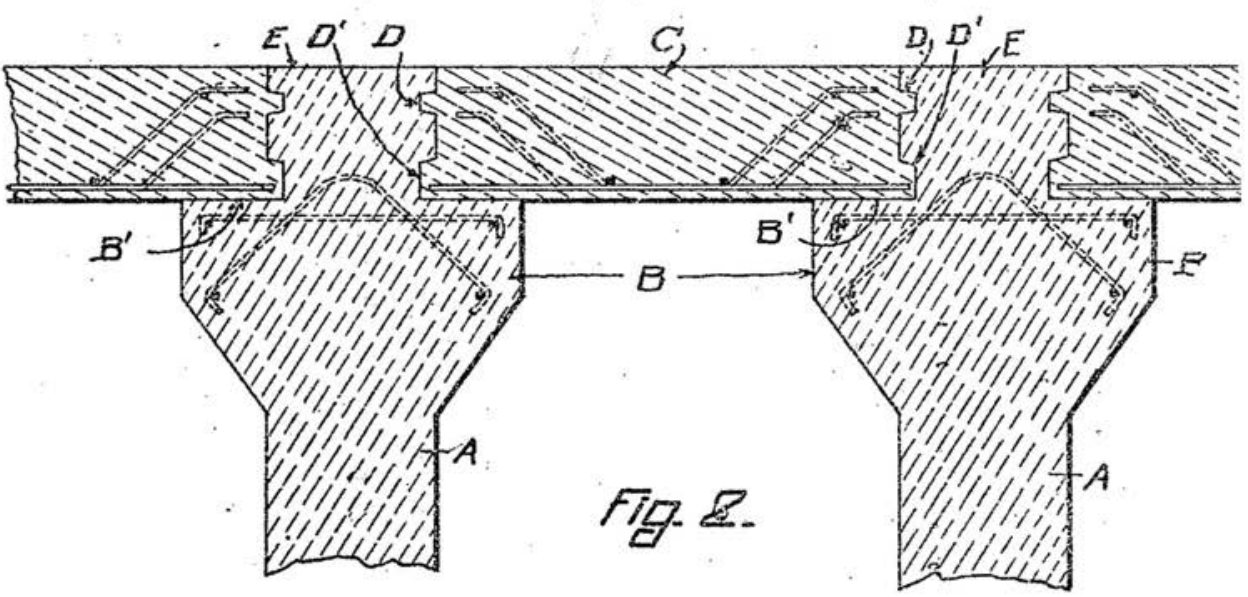

WITMESTES:

INVENTIRP

Figura 4. Patente de la compañía Ambursen de presa de contrafuertes con losa de hormigón reforzado y núcleo hueco. Fuente: www.freepatentsonline.com.

ronación. No obstante, sí se ha descartado Gaitanejo como antecedente real de La Jándula debido, entre otros motivos, a la diferencia de altura, aún menos debería contemplarse esta obra norteamericana como posible influencia en la concepción de la central de La Jándula, más allá de aspectos formales, como se ha advertido.

La integración de la central en el cuerpo de presa es una solución a la que se presta una familia de presas, ciertamente singular y escasamente representada. Se trata de las presas de cúpulas o bóvedas múltiples apoyadas sobre contrafuertes. En efecto, este tipo constructivo es una variación de las pre- sas de contrafuertes en las que los tramos de paramento entre un contrafuerte y el contiguo se resuelven mediante arcos o cúpulas, según los casos. Los huecos existentes entre contrafuertes en algunas ocasiones acogen las salas de turbinas. $\mathrm{Si}$ bien no es una realización análoga a la presa de La Jándula, conceptualmente sí presenta importantes similitudes en la integración de la central.

Este tipo constructivo cuenta con dos realizaciones muy tempranas y muy notables por su resultado estético y la dimensión del salto hidráulico conseguido. La primera de ellas es la presa italiana de Santa Clara de Ula, construida entre 

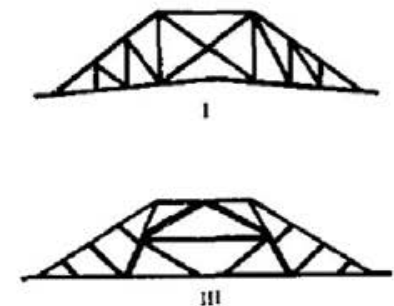
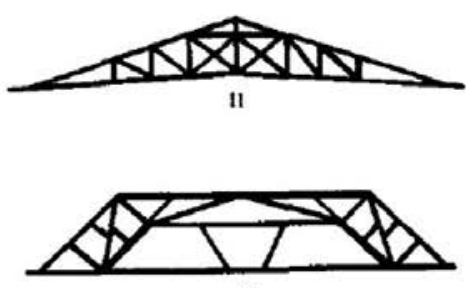

iv

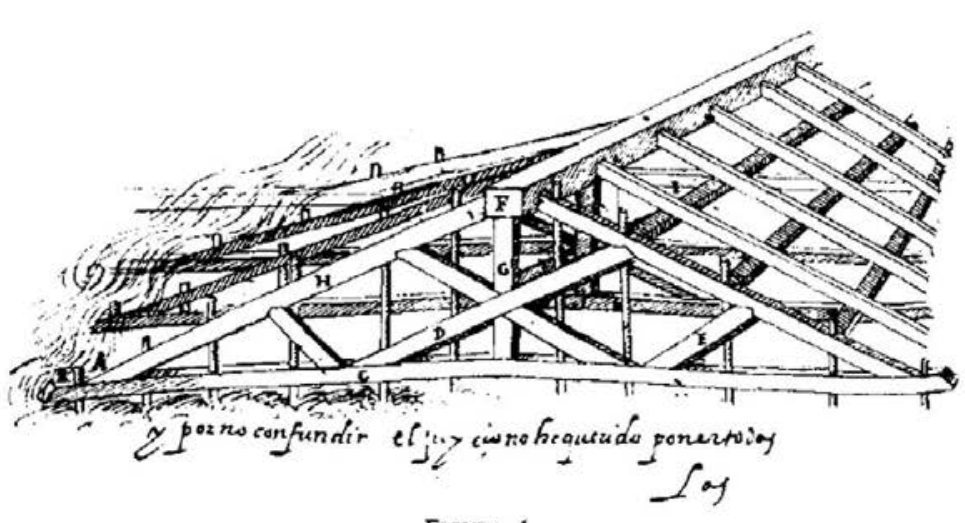

Figura 4
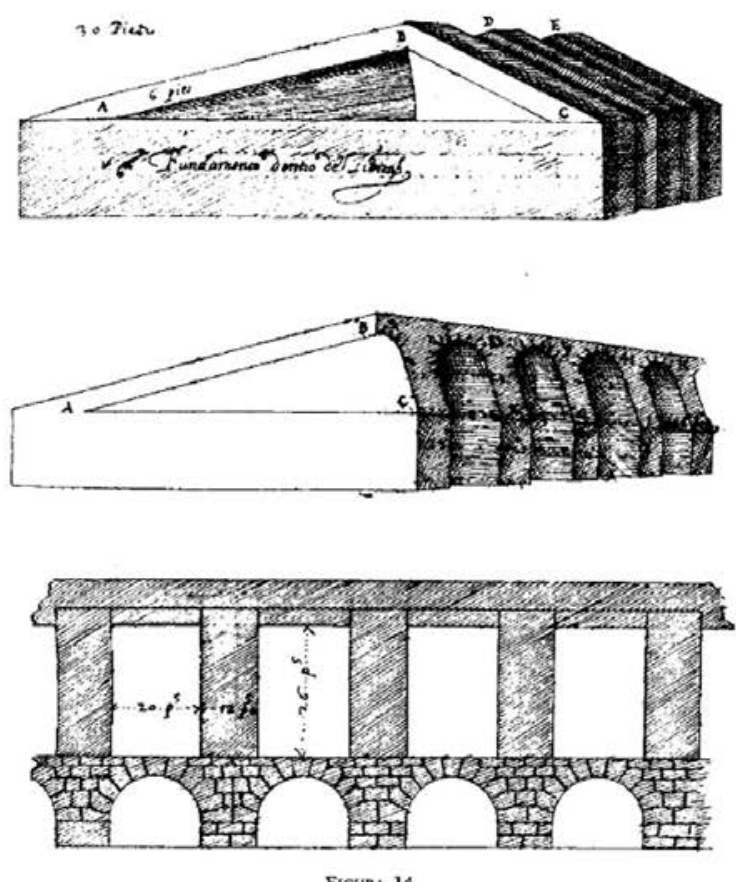

Figura 5. Dos soluciones de presas con núcleo hueco representadas por Juanelo Turriano en el siglo XVI.
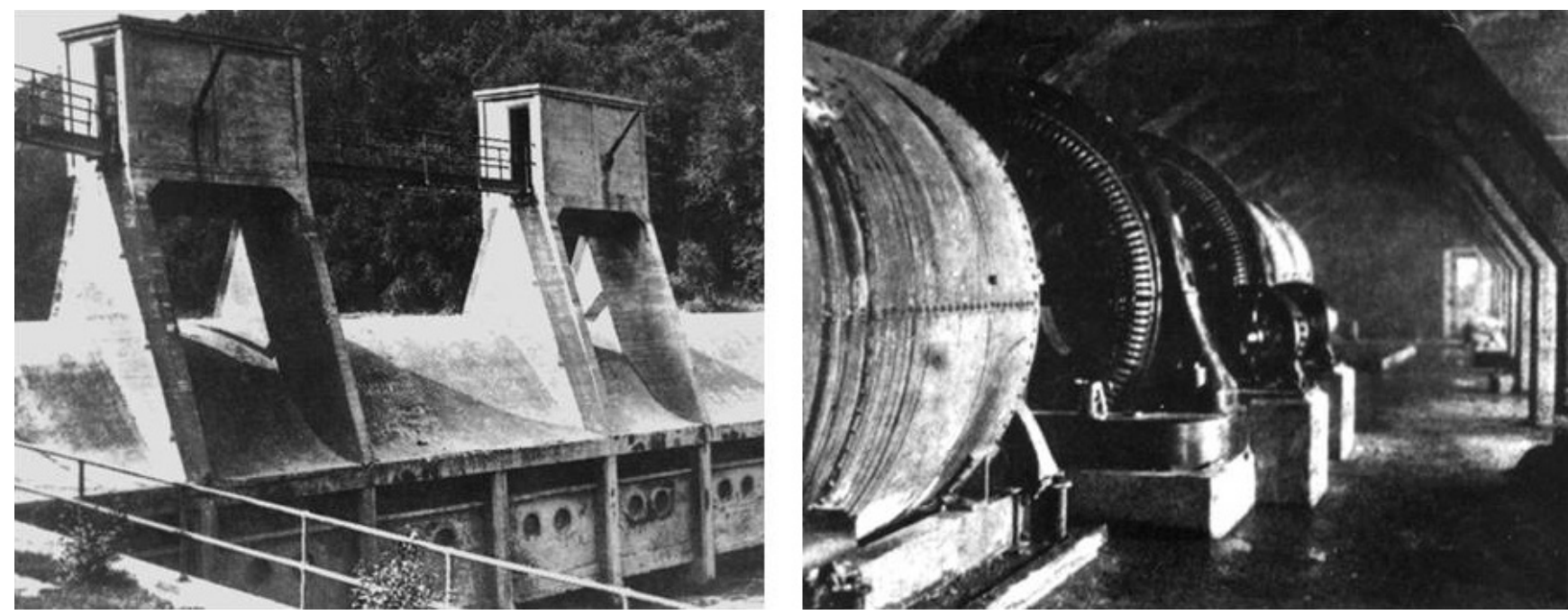

Figuras 6 y 7. Imagen de archivo de Bloeme's dam. Actualmente ha perdido ambas torres.

Interior de la presa en el que se ubican las turbinas.

1918 y 1924 sobre el río Tirso, en el sector central de la isla de Cerdeña (véanse Figuras 8, 9 y 10). Esta obra muestra una solución de bóvedas múltiples de hormigón, apoyadas sobre contrafuertes de mampostería. En su diseño y construcción intervinieron los insignes ingenieros italianos Luigi Kambo y Angelo Omodeo. La obra fue la primera de este tipo en Italia y la más alta del mundo, con $61 \mathrm{~m}$. Además, introduce un novedoso sistema de compuertas balancín, con sector flotante, utilizado muy escasamente en el mundo hasta esa fecha (20) (un año después España lo integraría en las compuertas del aliviadero de la presa de Camarasa).

El mismo año en que se acaban los trabajos en Cerdeña comienza la construcción de la presa de Coolidge en el Estado de Arizona, en EE.UU. Esta presa, diseñada por el ingeniero Herman Neuffer, se inaugura en 1930 y consigue la sublimación estética de este tipo estructural mediante una sucesión de tres bóvedas de hormigón magníficas apoyadas sobre contrafuertes (véanse Figuras 11, 12 y 13). La presa alcanza los $76 \mathrm{~m}$ de altura y cuenta con dos grandes aliviaderos laterales, uno en cada estribo. La central es un edificio encajado entre dos contrafuertes, aunque no queda integrada estrictamente dentro del cuerpo de presa, debido a la estructura hueca de la misma.

No se tiene constancia de la existencia de otras presas de estética similar a La Jándula y de entidad suficiente, con una solución igual o aproximada de incorporación de la central en su estructura. Esta carencia de antecedentes claros corrobora la idea de la novedad tipológica que introduce La Jándula en la historia de la ingeniería de presas en todo el mundo y demuestra la calidad técnica y compositiva de sus autores, el ingeniero Antonio del Águila y el arquitecto Casto Fernández-Shaw. A este último se le atribuye la solución final de integración de la central, el elemento más representativo 

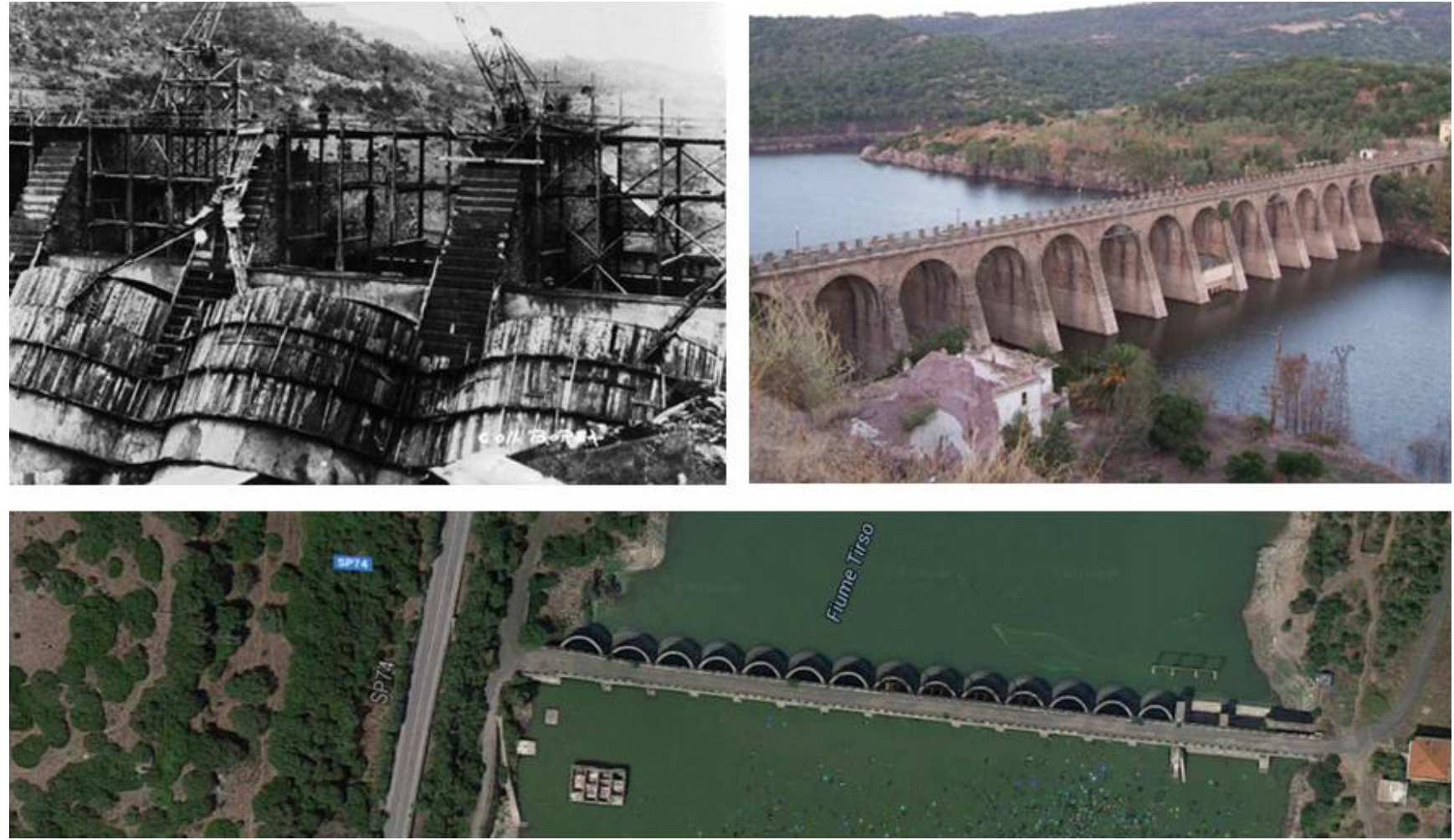

Figuras 8, 9 y 10. De izquierda a derecha y de arriba abajo. Detalle del encofrado de las bóvedas de la presa italiana de Santa Clara de Ula. Vista general de la presa con la sala de máquinas en el vano central. Imagen aérea en la que puede apreciarse la curvatura de las bóvedas (Fuente: Google Earth).
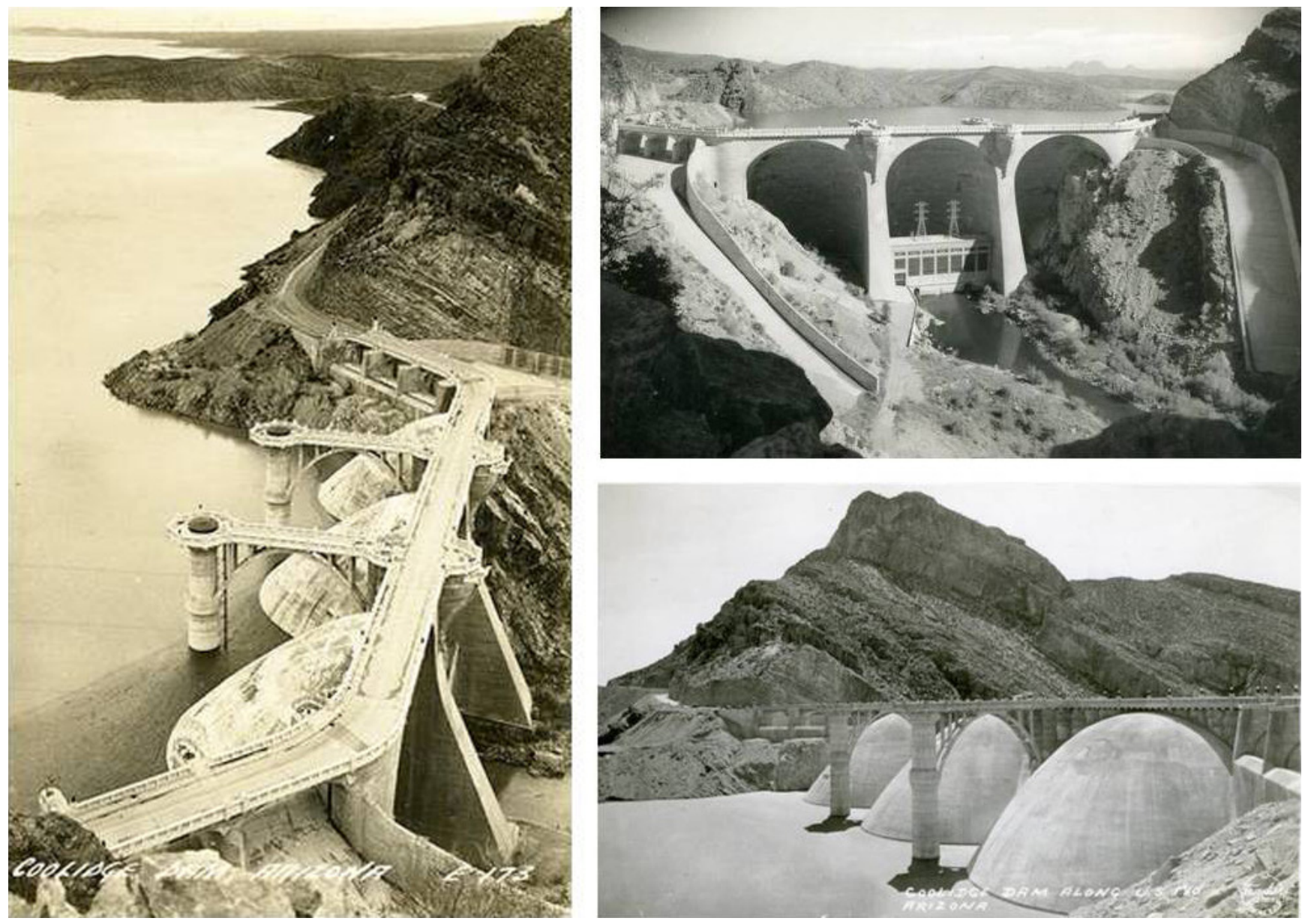

Figuras 11, 12 y 13. Imágenes históricas de la presa de bóvedas múltiples de Coolidge (Fuente: Flickriver) (21). 
y singular de la obra, y el tratamiento estético general de la obra, de una expresividad conmovedora.

Es preciso incidir en este punto en el conocimiento que los autores implicados en la presa de La Jándula tenían del estado de la técnica a nivel internacional. En efecto, son escasas pero significativas las referencias en este sentido. Valga como ejemplo la descripción de Magín Coello Fernández (22) en relación con el viaje que realizan D. Miguel Otamendi y D. Antonio González Echarte (Mengemor) a la Exposición Internacional de San Luis (EE.UU.) en 1904, precisamente en el año en que se registra la patente de Ambursen.

\section{LA JÁNDULA, CASTO FERNÁNDEZ-SHAW Y LA ARQUITECTURA INGENIERIL}

\subsection{La Jándula}

La presa de La Jándula sobre el río del mismo nombre en el municipio de Andújar (Jaén), también conocida como de La Lancha por ejecutarse sobre la cerrada granítica de dicho topó- nimo, es de tipología de gravedad, sección triangular - con taludes de sus paramentos estrictos según las teorías vigentes de 0,75 aguas abajo y 0,03 aguas arriba- y de planta ligeramente curva (véanse las Figuras 14 y 15). Con una altura de 83,5 m sobre el cauce y $90 \mathrm{~m}$ de altura sobre cimientos, fue de las más altas en su época. Tiene una longitud en coronación de 260 m (1).

El salto está inscrito en el Catálogo General del Patrimonio Histórico Andaluz, en la categoría general de acuerdo con el BOJA de 16 de marzo de 2006, página 53, por su caracterización arquitectónica como «bien inmueble del Movimiento Moderno» (23) (24).

El embalse tiene una capacidad de $322 \mathrm{hm}^{3}$, una superficie máxima de 1.350 ha, una longitud del embalse a lo largo del río de $18 \mathrm{~km}$ y un perímetro o costa de $69 \mathrm{~km} \mathrm{(25).} \mathrm{Su} \mathrm{cuenca}$ es de $2.278 \mathrm{~km}^{2}$ (6) con una precipitación media de $521 \mathrm{l} / \mathrm{m}^{2}$ y una aportación media anual de $184 \mathrm{hm}^{3}$ (11).

Dispone de un aliviadero en superficie con una capacidad de desagüe de $1.200 \mathrm{~m}^{3} / \mathrm{s}(6)$, con dos vanos, situado sobre la mar-

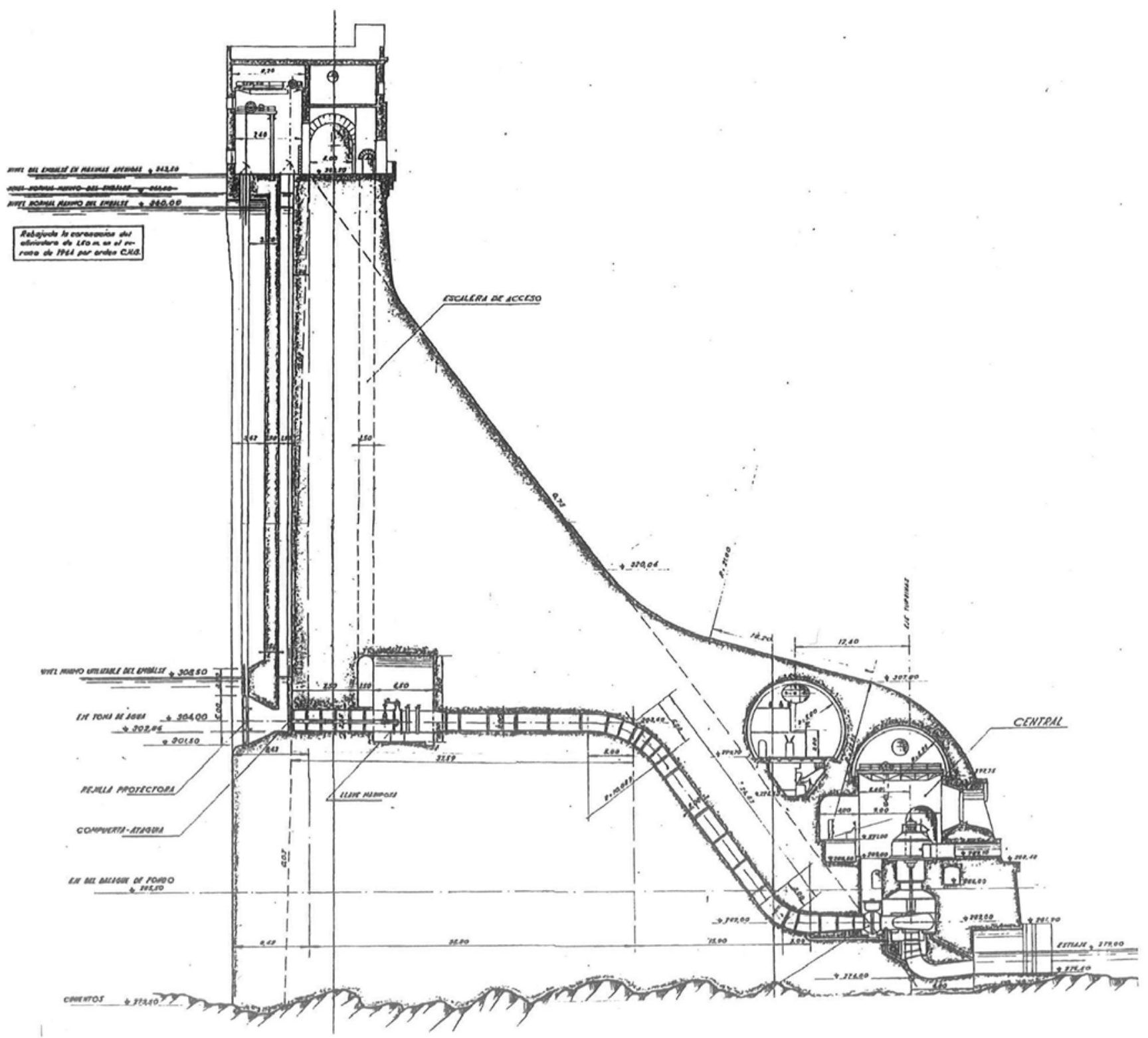

Figura 14. Sección transversal de la presa de La Jándula (Fuente: Fondo Histórico de la Fundación Endesa). 
gen derecha y fuera del cuerpo de la presa de labio fijo. El primero de los vanos, en canal al aire libre, se sitúa en una orientación, en relación con la corriente, frontal-lateral y forma en su desarrollo un ángulo recto adosándose a la falda de la cerrada. El cajero derecho y la solera son de roca y el cajero izquierdo es un muro de sección asimétrica, vertical en su interior y con talud casi vertical hacia el exterior, de hormigón y mampostería de granito. La longitud de este canal es de unos $110 \mathrm{~m}$ y su anchura de $15 \mathrm{~m}$. Este canal fue ensayado en el laboratorio de hidraúlica de Karlsruhe (Alemania) en los años 20 (11).

El otro vano del aliviadero se sitúa en una posición prácticamente frontal respecto a la corriente, consta de dos tramos, el primero en canal a cielo abierto y el segundo en túnel excavado en la montaña de unos $150 \mathrm{~m}$ de longitud. Este significativo túnel de granito visto tiene sección en forma de herradura con una anchura de $9 \mathrm{~m}$ y una altura aproximada de 7,4 $\mathrm{m}$.

Ambos canales circulan en paralelo con una suave pendiente vertiendo en una plataforma de descarga horizontal que se construyó en la margen derecha de la cerrada, desde allí, y con una caída de unos $75 \mathrm{~m}$, las aguas se vierten libremente al cauce original del río.

Los desagües de fondo, con una capacidad máxima de desagüe de $55 \mathrm{~m}^{3} / \mathrm{s}$, son ocho conductos de $600 \mathrm{~mm}$, dos de los cuales están a una cota superior, 281,41 y 284,01, respectivamente. Todos los conductos disponen de una compuerta accionada manualmente desde el vial de coronación. Los seis conductos centrales se unen en su extremo por parejas formando tres tubos de diámetro $850 \mathrm{~mm}$, en tanto que los extremos permanecen independientes y con la misma sección en toda su longitud. El control de estos desagües es doble, a través de las compuertas de paramento aguas arriba y mediante juegos de válvulas una vez han sido agrupados (11).

Su finalidad es la regulación y la producción de energía eléctrica. La central dispone de dos turbinas de $7.500 \mathrm{kVA}$ y otra de 3.500 kVA generando energía en una cuantía variable en función de los volúmenes almacenados con una producción de $15.000 \mathrm{~kW}$.

Iniciado el expediente en 1919, la concesión de la presa, en 1925, fue a favor de compañía eléctrica Mengemor dentro del expediente de Canalización y Aprovechamiento de Energía entre Córdoba y Sevilla. Para afrontar el proyecto Mengemor y dos grandes bancos fundan la sociedad Canalización y Fuerzas del Guadalquivir que inició las obras en febrero de 1926; en agosto de 1930 comenzó a prestar servicio la central concluyéndose las obras el 30 de junio de 1931 (22).

En su construcción se emplearon $263.000 \mathrm{~m}^{3}$ de hormigón ciclópeo revestido de sillería de granito labrada que se utilizó como encofrado. La presa carece de galerías de drenaje y auscultación y de galerías de comunicación en el cuerpo de la misma a excepción de una galería de comunicación desde la cámara para el gobierno de las válvulas de mariposa de las tomas hidroeléctricas a la coronación en el torreón de maniobra. Las juntas de dilatación son siete, separadas 15,55 m en las dos primeras del estribo izquierdo y $31,5 \mathrm{~m}$ en las restantes. Estas juntas se ejecutaron con chapas de plomo y un pozo de impermeabilización de arcilla (11).

Su coste fue de 22,8 millones de pesetas de los años 1926 a 1931.

\subsection{Casto Fernández-Shaw y la Arquitectura Ingenieril}

El arquitecto Casto Fernández-Shaw se incorpora al equipo de redacción del proyecto de la presa de La Jándula en torno a 1926, momento en el que se redefinen elementos esenciales de la obra, tales como los órganos de desagüe, la torre de maniobras y la central, modificando completamente la composición final de la obra. Los planos de las versiones anteriores recogen un edificio de máquinas situado aguas abajo del pie

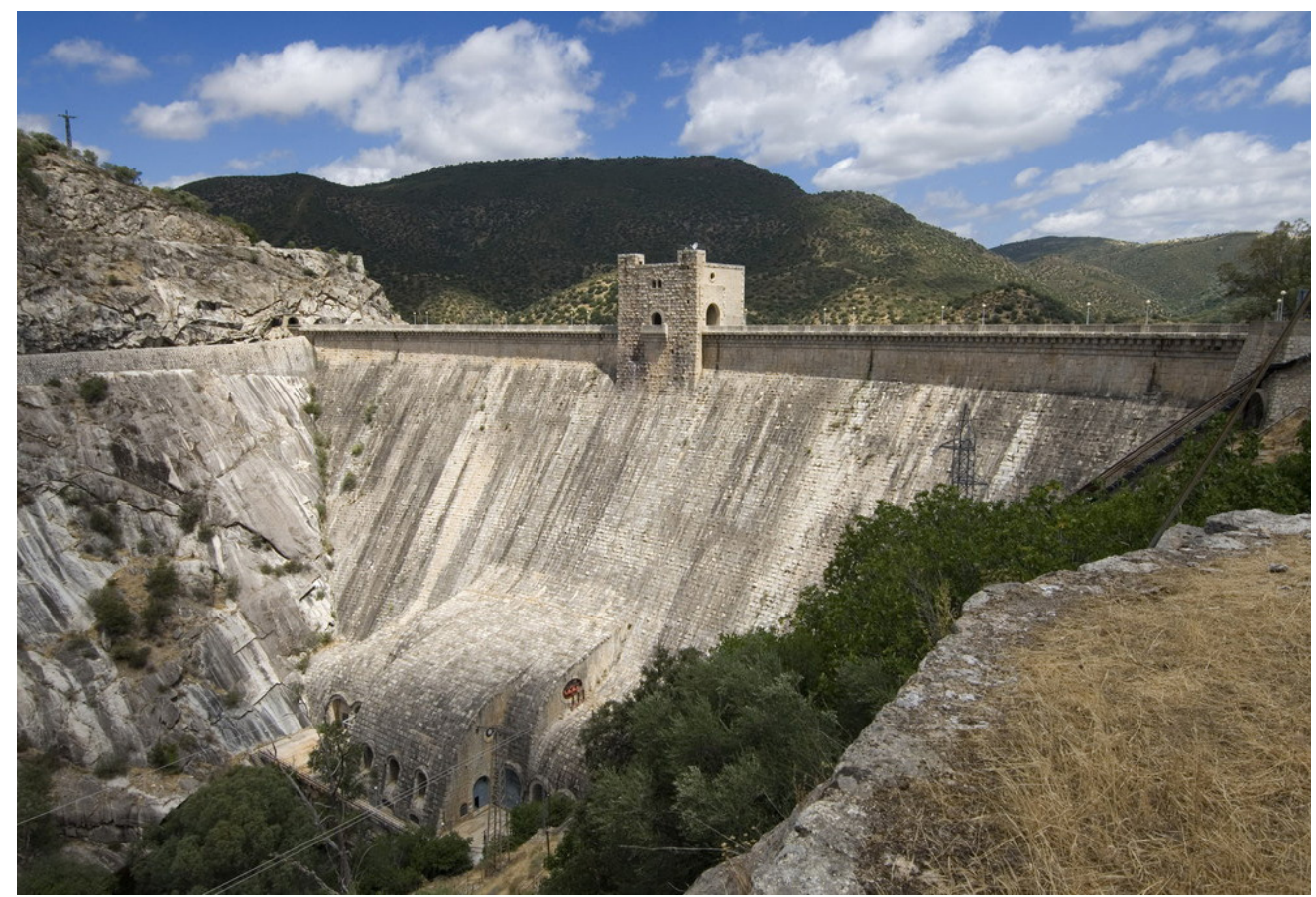

Figura 15. Vista general de la presa de La Jándula (Fuente: Instituto Andaluz del Patrimonio Histórico; autor: J. C. Cazalla Montijano) (23). 
de presa, sobre una de las márgenes, primero a escasos $15 \mathrm{~m}$ y después alejado unos $500 \mathrm{~m}$ de la pantalla. La ubicación de la sala de máquinas, efectivamente, debió ser una de las cuestiones más controvertidas del proyecto, debido a la angostura de la cerrada.

Esta última fase de definición de la estructura, correspondiente al periodo 1925-1927, integra el trabajo de diferentes profesionales. Antonio del Águila Rada lidera el equipo de ingeniería bajo las órdenes de uno de los ingenieros cofundadores de la empresa Mengemor, concesionaria del proyecto, Carlos Mendoza. Casto Fernández-Shaw entra a formar parte del equipo, después de algunas aportaciones externas, como arquitecto (26). La participación de un arquitecto en la redacción de un proyecto de ingeniería hidráulica no fue, ni lamentablemente lo es actualmente, una práctica común (27) (28). Sin embargo, Carlos Mendoza había conocido su proyecto Monumento al triunfo de la Civilización, a las grandes conquistas de la Idea y a la victoria del Hombre sobre la Naturaleza en la Exposición Universal de Bellas Artes de 1920. Se trata de un dibujo de una gran presa en la que una figura humana, en representación alegórica de toda la humanidad, sostiene el muro de contención, soportando simbólicamente el empuje de las aguas. El ingeniero quedó impactado por la fuerza y expresividad de la obra y decidió contactar con Shaw mostrándole su admiración y asombro por ver un arquitecto que proyecta presas (29). Es muy probable que Carlos Mendoza conociese el trabajo de Fernández-Shaw antes de la Exposición Universal, puesto que el arquitecto venía trabajando desde hacía tiempo en la oficina de los hermanos Otamendi, con quienes mantenía excelentes relaciones (véase la Figura 2).

La Memoria del proyecto presentado en 1927 recoge específicamente la definitiva posición de la sala de máquinas y revela la necesidad de dotarla de un perfil hidrodinámico para asumir eventuales desbordamientos sobre coronación durante la ejecución de las obras (8). Este hecho es muy relevante, puesto que es la fase de obra la que condiciona la forma definitiva del paramento inferior de la presa y, por tanto, de la central integrada. Es probable que éste sea el momento en que el arquitecto Fernández-Shaw se haga cargo de manera específica del diseño de la central y de su encaje en la presa. De este periodo es un dibujo del arquitecto en el que plantea una central con influencias claramente futuristas, una estética aún muy alejada de la solución final (véase Figura 16). Y éste es, en suma, el momento en el que una obra de ingeniería civil pasa a ser un proyecto de arquitectura; en el que ambas disciplinas alcanzan un grado de imbricación perfecto, logrando un resultado racional, funcional y bello.

Casto Fernández-Shaw es perfectamente consciente de la nueva arquitectura que suponía su incursión en el campo de la ingeniería civil, no sólo en la presa de La Jándula, sino también en la del Carpio, en la que ya había intervenido y en la de Alcalá del Río, donde participará después. En este sentido, él mismo describió su obra como ingeniería arquitectura o arquitectura ingenieril. No será la única dualidad de la obra y pensamiento de Fernández-Shaw, bien al contrario, la bipolaridad de sus intervenciones resulta una de sus señas de identidad y de las razones de su genialidad. El nombre y la filosofía de la revista que fundó en 1930, Cortijos y rascacielos (19301954), es claro ejemplo de su cosmovisión dual. Un enfoque interesado por la arquitectura vernácula, la herencia cultural y lo historicista, pero a la vez una mirada informada de las corrientes contemporáneas, cosmopolita e internacional.

En la presa de La Jándula la dicotomía conceptual a la que se ha referido se manifiesta en el manejo de dos estilos bien

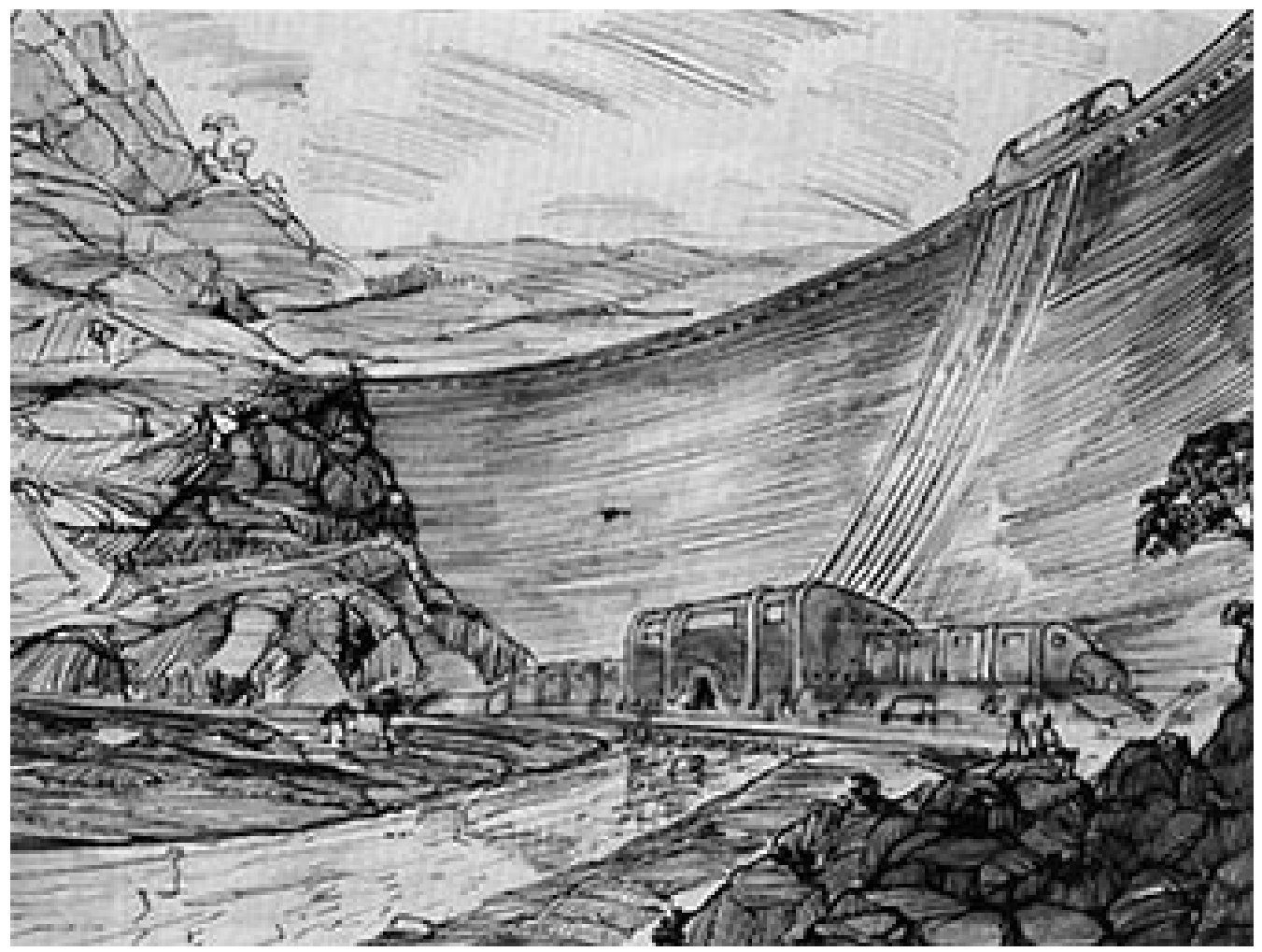

Figura 16. Único boceto del que se tiene constancia realizado por Fernández-Shaw. Apréciese que el diseño propuesto dista mucho de la solución final construida, aunque ya se ensaya con las formas futuristas y dinámicas de la sala de máquinas. 
diferentes, el historicista de la torre de maniobras, de los almohadillados de los sillares del paramento y de los remates almenados del antepecho de la línea de coronación, y el vanguardista, de formas hidrodinámicas y náuticas, de los espacios que acogen la sala de máquinas. Fernández-Shaw, fiel a la impronta que caracteriza toda su obra, huye de lo vulgar, de lo anodino y opta por trabajar la obra como monumento, enfatizando su altura y su volumen. Apasionado de los castillos medievales (funda la Sociedad de Amigos de los Castillos), de su carga solemne y sobrecogedora, acentúa el dominio del hombre sobre las fuerzas de la naturaleza que supone La Jándula replicando modelos pétreos de estructuras defensivas. A su vez, consciente de la vanguardia de las soluciones ingenieriles e hidrodinámicas introducidas en la presa, propone elementos que evocan submarinos, cápsulas futuristas de un aspecto casi espacial. Y lo más fascinante es su capacidad para combinar ambas tendencias de una forma audaz y brillante.

Otras presas se construyeron en Francia poco después aplicando la misma solución que se había ensayado en La Jándula, combinando además el trabajo de ingenieros y arquitectos. No se tiene la certeza de que sus diseños respondiesen al modelo español, pero el éxito y la trascendencia de La Jándula hacen suponer que la solución desarrollada por FernándezShaw inspiró, por un lado, la inclusión de la sala de máquinas en los cuerpos de las presas de Genissiat (1937-1947), L'Aigle (1947) y Saint-Etienne (1947), y por otro, la intención de potenciar la fuerza expresiva de los elementos hidráulicos y estructurales de las mismas.

\section{CONCLUSIONES}

Todos los motivos expuestos en estas líneas en relación con la innovación de La Jándula conducen a afirmar que esta obra es un referente obligado en la historia de la ingeniería hidráulica mundial. El arrojo proyectual con el que se definen las soluciones finales de sus elementos hidráulicos, de su perfil y su alzado y, sobre todo, de la integración de la central hidroeléctrica en el cuerpo de presa hacen de la obra una de las más importantes en su tipología.

La colaboración de la arquitectura y la ingeniería logran en esta obra la sublimación de sus aspectos técnicos y estéticos, y suponen un modelo insuficientemente seguido en España y en el extranjero. El término de ingeniería arquitectura inventado por Shaw no fue finalmente acuñado como referencia estilística, pero no cabe duda de que la colaboración del arquitecto en las definiciones formales de los ingenieros hidráulicos de la época dio como resultado un tipo de obra civil a medio camino entre la sobriedad del pragmatismo ingenieril e industrial y el arte de las creaciones arquitectónicas.

\section{REFERENCIAS}

(1) Díez-Cascón Sagrado, J. (2001). Ingeniería de presas. Presas de fábrica. Servicio de Publicaciones, Universidad de Cantabria.

(2) Díez-Cascón Sagrado, J., Bueno Hernández, F. (2003). Las presas y embalses en España: historia de una necesidad. Centro de Publicaciones, Ministerio de Medio Ambiente.

(3) Billington, D. P., Jackson, D. C., Melosi, M. V. (2005). The history of the Large Federal Dams: planning, design and construction in the Era of Big Dams, 605 pp. Denver (Colorado): U.S. Department of the Interior. Bureau of Reclamation.

(4) Wegmann, E. (1922). The Design and Construction of Dams, $7 \cdot^{\mathrm{a}}$ edición. New York, USA: John Wiley \& Sons.

(5) Sociedad Española de Presas y Embalses. www.seprem.es

(6) García Diego, J. A. (1994). Presas antiguas de Extremadura. Madrid: Fundación Juanelo Turriano.

(7) DGOH. (2001). Inventario de Presas y Embalses. http://sig.mapama.es/snczi

(8) Bestué Cardiel, I. (coord.) (2007). Salto hidroeléctrico de El Chorro. Estudio para la restauración del «Caminito del Rey». CEHOPU.

(9) Gaite, M. (1977). El Conde de Guadalhorce: su época y su labor. Editorial del Colegio de Canales, Caminos y Puertos.

(10) Bernal, A. M. (1993). Ingenieros-empresarios en el desarrollo del sector eléctrico español: Mengemor, 1904-1951. Revista de Historia Industrial, 3: 93-126.

(11) Carbajal Ballell, N. (2014). Fernández-Shaw: el salto del Jándula. Andújar, 1927. Casto Fernández-Shaw, Carlos Mendoza y otros. Edita Colegio Oficial de Arquitectos de Almería.

(12) Carbajal Ballell N. J. (2015). El Salto del Jándula. Génesis de un paisaje (Tesis doctoral), pp. 87-101. Escuela Técnica Superior de Arquitectura, Departamento de Proyectos Arquitectónicos, Universidad de Sevilla.

(13) Reportaje fotográfico de la obra. Cía. de Canalización y Fuerzas del Guadalquivir, 1929

(14) Gómez Navarro, J. L., Aracil, J. J. (1952). Saltos de agua y presas de embalse, tercera edición, tomo primero, pp. 10671168.

(15) Bloede, V. C. (1996). The journey: Victor G. Bloede, his forebears \& successors.

(16) Recursos online de la Biblioteca Pública del Condado de Baltimore (EE.UU.). http://www.bcpl.info/

(17) Jackson, D. C. (2005). Building the Ultimate Dam: John S. Eastwood and the Control of Water in the West, p. 295.

(18) Ambursen Hydraulic Construction Company (1912). Ambursen dams, p. 63. Boston: University of Minnesota. Digitalizado por Google.

(19) García-Diego, J. A. (1983). El capítulo sobre azudes del código de Juanelo Turriano. En Anales Toledanos, 16: 189-210.

(20) Santasusana, L., Diz Bercedoniz, M. (1926). La instalación de compuertas automáticas de sector flotante en la presa de Camarasa. En Ingeniería y Construcción, IV(37).

(21) www.flickriver.com

(22) Coello Fernández, M. (200o). El fantasma del metro de Madrid. Excelentísimo y muy olvidado señor González Echarte, 1864-1942, 330 pp. Ederonio, S. L. 
(23) Ficha de catalogación del Salto del Jándula. Patrimonio Inmueble de Andalucía. Instituto Andaluz del Patrimonio Histórico. Consejería de Cultura, Junta de Andalucía.

(24) Inscripción con carácter general del Salto del Jándula en el Catálogo General del Patrimonio Histórico Andaluz. BOJA, núm. 51, de 16 de marzo de 2006, pp 53-54.

(25) Almendral, J. M. (1986). Jaén desde sus obras públicas. Editorial del Colegio de Ingenieros de Caminos, Canales y Puertos, pp. 138, 139 y 248.

(26) Galnares del Coso, V. M., García Redondo, N., Gutiérrez Abad, A. (1996). Presa de Jándula y la canalización del Guadalquivir. Revista de Obras Públicas, 143(3356): 81-90.

(27) Molina Sánchez, J. (2015). Arquitectura e Ingeniería en las presas y centrales hidroeléctricas. En Navascués, P., Revuelta, B. (cords.), Ingenieros Arquitectos. Fundación Juanelo Turriano.

(28) Molina Sánchez, J. (21-23 de noviembre 2013). Arquitectura, paisaje y construcción en las presas y centrales hidroeléctricas españolas del siglo XX. En I Seminario Internacional sobre Patrimonio de la Arquitectura y la Industria (pp. 104-105). Madrid.

(29) Barrionuevo, A. (1980). La central hidroeléctrica y el embalse del Jándula y Casto Fernández-Shaw. Revista Guadalquivir (6). 